\title{
IMPLEMENTASI PERANGKAT PEMBELAJARAN BERBASIS MASALAH PADA SISWA KELAS V SEKOLAH DASAR
}

\author{
Ghullam Hamdu' ${ }^{1)}$,Anggi Lestari' ${ }^{2)}$ Nisa Nurlaila ${ }^{3)}$ \\ 1)ghullamh2012@upi.edu 2)giw_gie27@yahoo.co.id 3)nisanurlaila18@gmail.com \\ UPIKampusTasikmalaya
}

\begin{abstract}
Problem based learning program have been developed devices based learning thematic issue results in a product that has a valid learning tool and fit for use. Problem-based learning device is then implemented in the school by the class teacher $V$. Results of learning implementation is processed and analyzed based on the learning outcomes achieved by students. The implementation process of the learning device is performed using pre-experimental methods. By comparing the results of the pretest and posttest. Problem is used which is about the high level (HOTS). Assessment of performance and attitude observed during the implementation of learning by using a rubric. Results indicate where there is a yield increase of students' higher-order thinking. However, students have not been accustomed to solving problems based on higher-level thinking. It can be based on the value obtained from the pretest and posttes students. The results of the performance and attitude of students during the learning process showed positive results that students can attend with good problem-based learning.

Keywords: thematic, assessment of performance and attitudes, problem based learning
\end{abstract}

Telah dikembangkan perangkat pembelajaran berbasis masalah secara tematik dengan hasil berupaprodukperangkatpembelajaran yang telah valid danlayakdigunakan. Perangkat pembelajaran berbasis masalah ini kemudian diimplementasikan di sekolah oleh guru kelas V. Hasil implementasi pembelajaran tersebut diolah dan dianalisis berdasarkan hasil pembelajaran yang dicapai siswa. Proses implementasi perangkat pembelajaran ini dilakukan menggunakan metode pre-eksperimen. Dengan membandingkan hasil pretest dan posttest. Soal yang digunakan yakni soal tingkat tinggi(HOTS). Penilaian kinerja dan penilaian sikap diamati selama pelaksanaan pembelajaran dengan menggunakan rubrik. Hasil menunjukkan bahawa terdapat peningkatan hasil dari berpikir tingkat tinggi siswa. Namun, siswa belum terbiasa menyelesaikan soal-soal berbasis berpikir tingkat tinggi. Hal ini dapat berdasarkan nilai yang diperoleh siswa dari pretes dan posttes. Hasil kinerja dan sikap siswa selama proses pembelajaran menujukkan hasil yang postif bahwa siswa dapat mengikuti pembelajaran berbasis masalah dengan baik.

Kata Kunci: tematik, penilaian kinerja dan sikap, pembelajaran berbasis masalah

\section{PENDAHULUAN}

Pelaksanaan Kurikulum 2013 pada Sekolah Dasar/Madrasah Ibtidaiyah dilakukan melalui pembelajaran dengan pendekatan tematik-terpadu dari Kelas I sampai Kelas VI (Salinan lampiran permendikbud no. 67 tahun 2013 tentang kurikulum SD). Dengan demikian pembelajaran pada kurikulum 2013 dilakukan dengan mengaitkan berbagai kompetensi dasar atau mata pelajaran yang masih satu konsep dalam satu tema tertentu. Pembelajaran dilakukan secara tematik agar pengetahuan yang dimiliki siswa mengenai suatu konsep dapat menyeluruh tidak terpisah pisah. Agar pembelajaran lebih bermakna pembelajaran harus dikaitan dengan permasalahan yang biasa dihadapi siswa sehari-hari. Untuk menemukan solusi dari permasalahan diperlukan pengetahuan yang menyeluruh dari suatu konsep.

Oemar Hamalik (Henawan et.al, 2007) menjelaskan bahwa pembelajaran merupakan prosedur dan metode yang ditempuh oleh pengajar untuk memberikan kemudahan bagi peserta didik untuk melakukan kegiatan belajar secara aktif dalam rangka mencapai tujuan pembelajaran. Oleh sebab itu, dalam proses pembelajaran siswa harus secara aktif mengalami sendiri untuk mencapai tujuan pembelajaran yang dirumuskan guru dan bukan hanya menerima dari pemberian guru. Pada proses pembelajaran siswa harus dibiasakan terlibat dalam memecahkan permasalahan-permasalahan. Saat proses belajar mengajar siswa banyak menerima teori dari guru, namun pada saat mereka 
dihadapkan pada suatu permasalahan mereka bingung menemukan solusi untuk menyelesaikannya. Mereka tidak tahu cara mengaplikasikan teori yang mereka dapat untuk menemukan solusi atas permasalahan yang dihadapi. Kurangnya aktivitas siswa dalam suatu pembelajaran menyebakan mereka hanya menghapal teori yang didapat tanpa memahaminya.

How we teach must also change in order to prepare our students to cope with these new situations: students need more than ever to be able to pose questions, seek and find appropriate resources for answering these questions, and communicate their solutions effectively to others. (Duch, et al, 2001)

Cara guru mengajar juga harus berubah untuk mempersiapkan siswa mengatasi situasi baru. Siswa perlu lebih dari sebelumnya untuk dapat mengajukan pertanyaan, mencari dan menemukan sumber daya yang tepat untuk menjawab pertanyaan-pertanyaan ini, dan mengkomunikasikan solusi mereka secara efektif kepada orang lain. Salah satu cara guru untuk membantu siswanya belajar memecahkan masalah adalah dengan menggunakan metode pembelajaran berbasis masalah (Problem Based Learning/PBL). It is crucial that the students in a PBL curriculum become lifelong learners who have learned to take responsibility for their own learning process (Graaff\&Kolmos, 2003).

Pembelajaran berbasis masalah lebih menitik beratkan pada proses kegiatan yang siswa lakukan dalam suatu pembelajaran (student centre). Melalui pembelajaran berbasis masalah siswa diajak untuk berpikir dan melakukan suatu aktivitas untuk menemukan solusi atas suatu permasalahan. Menurut Nasution (2011) "Masalah yang terpecahkan melalui problem solving mantap dan sukar dilupakan, apalagi bila mengenai pemikiran pada taraf tinggi". Apabila siswa terlibat langsung dalam memecahkan masalah maka pembelajaran akan lebih bermakna dan sulit untuk dilupakan, dibandingkan siswa hanya diberikan teori terus menerus tanpa adanya kegiatan yang dilakukan.

Esensi PBL berupa menyuguhkan berbagai situasi bermasalah yang autentik dan bermakna kepada siswa, yang dapat berfungsi sebagai batu loncatan untuk investigasi dan penyelidikan (Arends, 2008). Sedangkan menurut Dewey (dalam Sudjana 2006) belajar berdasarkan masalah adalah interaksi antara stimulus dengan respons, merupakan hubungan antara dua arah belajar dan lingkungan. Pada pembelajaran berbasis masalah siswa dituntut untuk dapat menginvestigasi, menyelidiki dan menyelesaikan suatu permasalahan yang disajikan oleh guru. Masalah dijadikan langkah awal siswa untuk merekonstruksi pengetahuan baru yang akan didapatnya. Masalah yang disajikan guru harus merupakan masalah yang konkret ada dalam dunia siswa. Salah satu cirri dari pembelajaran berbasis masalah adalah focus kepada keterkaitan berbagai disiplin ilmu (Nurha didalam Putra, J. D., 2013). Dengan demikian, berdasarkan uraian tersebut maka pembelajaran berbasis masalah sangat cocok apabila diterapkan dalam kurikulum 2013 yang menuntut pembelajaran secara tematik-integratif.

Namun permasalahan yang ada adalah keterbaruan kurikulum 2013 ini belum sepenuhnya diketahui oleh para guru di sekolah. Penerapan kurikulum ini pun baru secara bertahap diimplementasi di kelas kelas tertentu. Khusus untuk tingkat sekolah dasar hanya diterapkan pada kelas 1 dan kelas 4 di tahun pertama, dan diterapkan selanjutnya pada tahun kedua untuk kelas 1, 2, 4 dan 5 dan di tahun ketiga baru dilaksanakan secara menyeluruh di semua jenjang kelas. Atas dasar tersebut maka guru di lapangan memerlukan contoh yang kongkrit bagaimana pelaksanaan pembelajaran dengan menggunakan kurikulum 2013 ini, terlebih lagi membelajarkan dengan tematik di kelas atas (kelas 4, 5, dan 6) yang sebelumnya belum pernah dianjurkan pada kurikulum sebelumnya. 
Maka penelitian yang dilaksanakan ini untuk menggambarkan hasil implementasi dari hasil penelitian sebelumnya berupa perangkat pembelajaran berbasis masalah di kelas V Sekolah Dasar.Perangkat pembelajaran ini dilaksanakan dengan tema bermain dengan benda-benda sekitar. Basis pembahasan pelaksanaan pembelajaran tersebut dengan materi pembelajaran IPA yang kemudian dipadukan dengan beberapa mata pelajaran lain yang dapat mengadopsi proses pelaksanan pembelajaran yang sesuai.

\section{METODE}

Penelitian ini menggunakan motodepreeksperimen dengan desain one-group Pretestposttest. Dengan menurut Sugiono (2009) sebagai berikut.

\section{$\mathrm{O}_{1} \times \mathrm{O}_{2}$}

Keterangan :

$\mathrm{O} 1=$ nilai pretest

$\mathrm{O} 2=$ nilai posttest

$\mathrm{X}=$ treatment
Treatment yang diberikan berupa perangkat pembelajaran berbasis PBL. Yaitu perangkat pembelajaran yang bangkan dan dihasilkan dari penelitian sebelumnya berupa RPP, LKS, media, danasesmen. Implementasi perangkat sebagai treatment ini dilakukan di kelas V SDN Panglayungan Kota Tasikmalaya dengan jumlah siswa 20.

\section{HASIL DAN PEMBAHASAN}

Dari hasil penelitian ini berupa perangkat pembelajaran yang telah layak digunakan mencakup RPP, LKS, media, danAsesmen. Selanjutnya dilakukan implementasi perangkat pembelajaran tersebut di kelas V Sekolah Dasar. Berikut data dasil belajar siswa kelas V SDN Panglayungan Kota Tasikmalaya.

- Analisis terhadap hasil tes soal HOTS Pada tahap implementasi diawal dan diakhir siswa mengerjakan soal tes berbasis HOTS untuk mengukur keterampilan siswa dalam menjawab keterampilan tingkat tinggi. Berikut hasil analisis terhadap hasil tes soal HOTS.

Tabel 1

Data hasil pretes dan posttes

\begin{tabular}{|c|c|c|c|c|}
\hline No & Nama & Nilai Pretes & Nilai Posttes & Selisih Nilai \\
\hline 1 & Rahmi & 43 & 43 & 0 \\
\hline 2 & Ratih & 17 & 39 & 22 \\
\hline 3 & Azaria & 43 & 43 & 0 \\
\hline 4 & Arazka & 40 & 50 & 10 \\
\hline 5 & Cynthia & 57 & 60 & 3 \\
\hline 6 & Rona & 10 & 50 & 40 \\
\hline 7 & Neisa & 47 & 47 & 0 \\
\hline 8 & Alfasha & 50 & 56 & 6 \\
\hline 9 & Syakirah & 53 & 60 & 7 \\
\hline 10 & Olivia Novianti & 33 & 50 & 17 \\
\hline 11 & Ali & 30 & 36 & 6 \\
\hline 12 & M. Adhwa & 37 & 50 & 13 \\
\hline 13 & Ikbar & 36 & 36 & 0 \\
\hline 14 & Nabila shafa & 33 & 36 & 3 \\
\hline 15 & Dezan & 23 & 40 & 17 \\
\hline 16 & Daffa & 27 & 40 & 13 \\
\hline 17 & Zaskia R & 33 & 40 & 7 \\
\hline 18 & Nayla A & 67 & 67 & 0 \\
\hline 19 & M. Farhan & 36 & 50 & 14 \\
\hline 20 & Satrio & 37 & 50 & 13 \\
\hline
\end{tabular}


Dari hasil pretest dan postest dilihat terdapat kemajuan dalam siswa mengerjakan soal. Hal tersebut terlihat dari selisih atau interval nilai pretest dan postest. Interval paling tinggi yaitu 40 pada nilai pretest siswa mendapatnilai 10 dan posttest siswa mendapat nilai 50. Jadi pembelajaran berbasis masalah membantu siswa dalam mengembangkan keterampilan berpikir tingkat tinggi siswa. Dari nilai rata-rata yang kecil diperoleh oleh siswa sebelum dan sesudah pembelajaran menunjukan bahwa siswa belum terbiasa mengerjakan soal-soal tingkat tinggi. Dengan interval nilai maksimal penilaian tersebut adalah 100. Namun nilai pretes maksimal siswa 57 dan nilai posttes maksimal siswa 60 .
Sementara itu, dari 20 siswaterlihat $75 \%$ atausebanyak 15 siswa mengalami peningkatan hasil belajar. Hasil tersebut menunjukan bahwa perangkat pembelajaran berbasis masalah berhasil diimplementasikan dan layak digunakan.

\section{Analisis terhadap Asesmen kinerja}

Saat implementasi pembelajaran selama dua hari dilakukan penilaian kinerja siswa dengan menggunakan rubrik penilaian yang telah dikembangkan berdasarkan pembelajaran berbasis masalah. Berikut data penggunaan rubrik kinerja kelompok dalam pembelajaran berbasis masalah.

Gambar 1

Data Penilaian Kinerja Produk

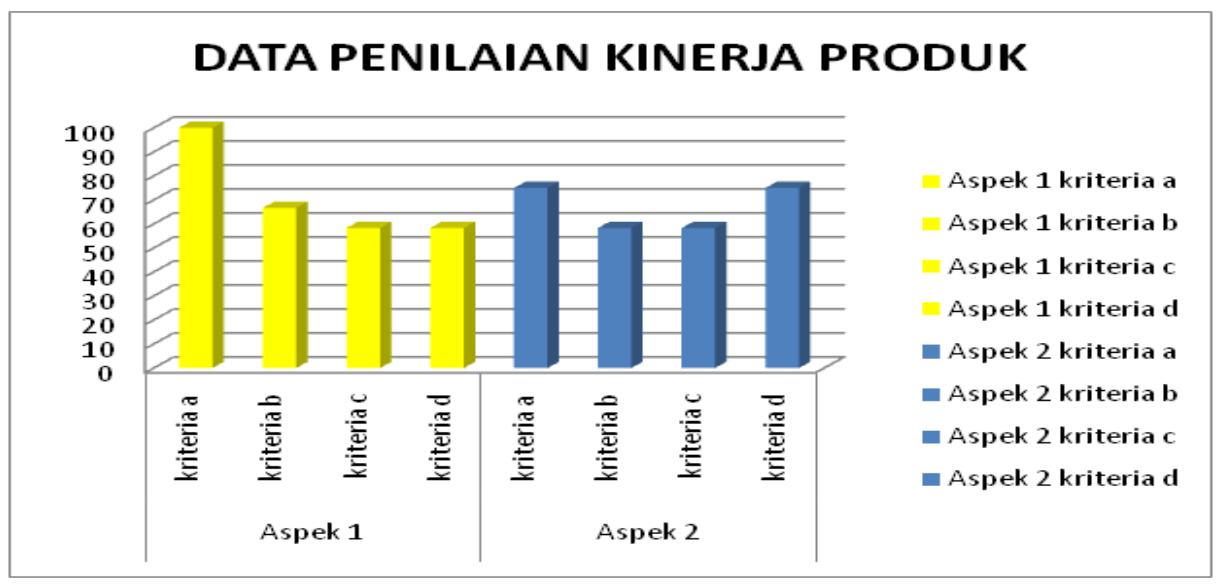

Tabel 2

Aspek dan Kriteria Kinerja Produk

\begin{tabular}{lll}
\hline \multicolumn{1}{c}{ Aspek } & \multicolumn{1}{c}{ Kriteria } \\
\hline $\begin{array}{l}\text { 1. Merangkai rangkaian } \\
\text { listrik dengan bahan } \\
\text { alami }\end{array}$ & a. & Kerapihan \\
\cline { 2 - 2 } & b. & Menggambar baterai pada titik A $(2,1)$ \\
\cline { 2 - 2 } & c. & Menggambar lampu pada bidang koordinat B $(1,3)$, C $(3,3)$ \\
\hline & d. & Menggambar kabel pada titik koordinat \\
\hline $\begin{array}{l}\text { 2. Menggambar Rangkaian } \\
\text { Listrik Paralel pada }\end{array}$ & a. & Menggambar bidang koordinat pada kertas kosong \\
Sistem Koordinat & bartesius & Menggambar baterai pada titik A (1,3) \\
\cline { 2 - 2 } & c. & Menggambar lampu pada bidang koordinat B $(3,2)$ C $(5,2)$ \\
\hline
\end{tabular}

Dari penilaian dengan menggunakan rubrik penilaian kinerja produk pada aspek 1 paling tinggi yaitu kriteria a yaitu kerapihan dalam pembuatan produk dan pada aspek 2 paling tinggi yaitu kriteria d yaitu menggambar kabel pada titik koordinat.

Pada penggunaan rubrik asesmen kinerja kelompok terdapat 3 aspek. Pada aspek 
1 paling tinggi yaitu kriteria a, c, dan $d$ saat siswa mengidentifikasi listrik statis. Pada aspek 2 yaitu kriteria d dan e saat siswa mengidentifikasi sumber arus listrik. Pada aspek 3 yaitu kriteria a saat siswa menampilkan hasil rangkaian listrik.

Gambar 2

Data Asesmen Kinerja kelompok

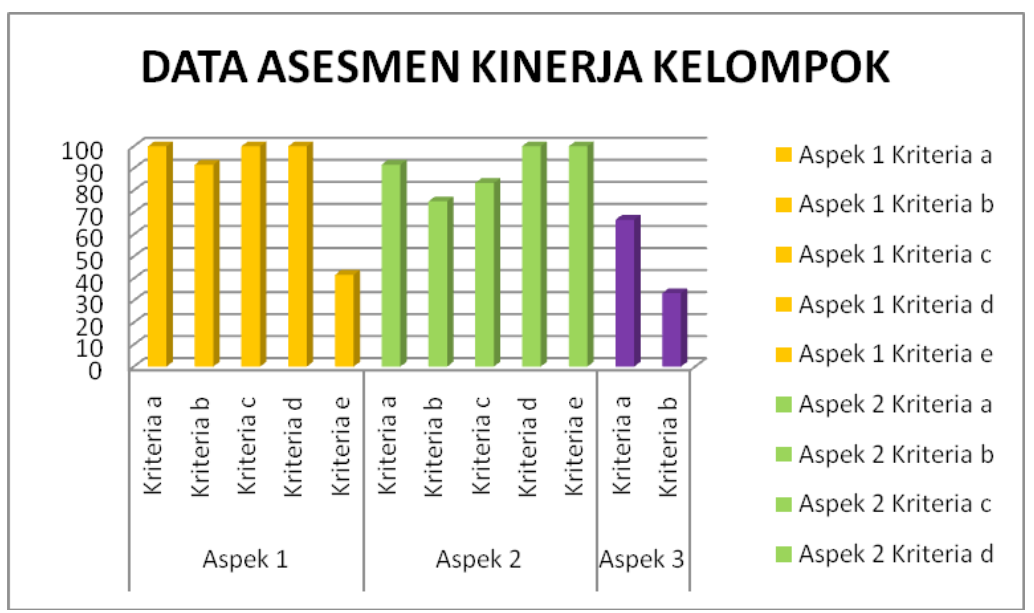

Tabel 3

Aspek dan Kriteria Kinerja Kelompok

\begin{tabular}{|c|c|}
\hline Aspek & Kriteria \\
\hline \multirow{5}{*}{$\begin{array}{l}\text { 1. Cara siswa mengidentifikasi listrik } \\
\text { statis melalui percobaan sederhana } \\
\text { dengan menggosokkan plastik } \\
\text { mika pada rambut, kemudian } \\
\text { didekatkan pada potongan } \\
\text { sterofoam dan kertas (mencoba, } \\
\text { elaborasi, mengolah) }\end{array}$} & $\begin{array}{l}\text { a. Menentukan alat dan bahan yakni: } \\
\text { Plastik mika, potongan kertas, rambut, dan potongan } \\
\text { sterofoam }\end{array}$ \\
\hline & b. Menggunakan alat dan bahan \\
\hline & $\begin{array}{l}\text { c. Memanipulasi alat dan bahan (menentukan besar potongan } \\
\text { kertas/sterofoam agar bisa ditarik oleh penggaris) }\end{array}$ \\
\hline & $\begin{array}{l}\text { d. Melakukan Percobaan yakni: } \\
\text { menggosokkan plastik mika pada rambut/kain/kulit dan } \\
\text { mendekatkannya pada potongan kertas atau sterofoam }\end{array}$ \\
\hline & $\begin{array}{l}\text { e. Mencatat hasil percobaan dengan waktu yang desediakan (10 } \\
\text { menit) }\end{array}$ \\
\hline \multirow{4}{*}{$\begin{array}{l}\text { 2. Cara siswa mengidentifikasi } \\
\text { mengidentifikasi macam-macam } \\
\text { sumber arus listrik dengan sayur } \\
\text { dan buah (mencoba, elaborasi, } \\
\text { mengolah) }\end{array}$} & $\begin{array}{l}\text { a. Menggunakan alat dan bahan yakni: } \\
\text { Paku seng, koin } 500 \text { kuning, lampu LED, penjepit buaya, } \\
\text { sayuran dan buah sebagai sumber arus listrik (kentang, apel, } \\
\text { jeruk nipis, belimbing wuluh dan singkong) }\end{array}$ \\
\hline & $\begin{array}{l}\text { b. MerangkaiPaku seng, koin } 500 \text { kuning, lampu LED, penjepit } \\
\text { buaya, sayuran dan buah sebagai sumber arus listrik } \\
\text { (kentang, apel, jeruk nipis, belimbing wuluh dan singkong) }\end{array}$ \\
\hline & $\begin{array}{l}\text { c. Melakukan Percobaan yakni: } \\
\text { kelompok berhasil meragkaikan sumber listrik yang } \\
\text { dicobakan, koin, paku seng, capit buaya dan lampu LED. }\end{array}$ \\
\hline & d. $\quad$ Mencatat hasil percobaa \\
\hline \multirow[t]{2}{*}{$\begin{array}{l}\text { 3. Menampilkan hasil rangkaiain listrik } \\
\text { dengan sumber listrik dari bahan } \\
\text { alami (jeruk, belimbing wuluh, } \\
\text { kentang, apel, dan mentimun) } \\
\text { (mengkomunikasikan dan } \\
\text { konfirmasi) }\end{array}$} & a. Bahasa yang digunakan ketika mempresentasikan \\
\hline & b. Konten yang disampaikan dalam presentasi \\
\hline
\end{tabular}


Keterangan Aspek Kinerja dalam Bersikap:

Aspek 1: Dsiplin dalam kegiatan pengamatan, percobaan dan pembelajaran

Aspek 2: Tanggungjawab dalam menyelesaikan tugas yang adapada LKS
Aspek 3: Bekerjasama dalam kelompok Aspek 4: Objektif dalam mengerjakan LKS Aspek 5: Rasa Hormatyang ditunjukkan selama pebelajaran

Pada penggunaan rubrik kinerja dalam

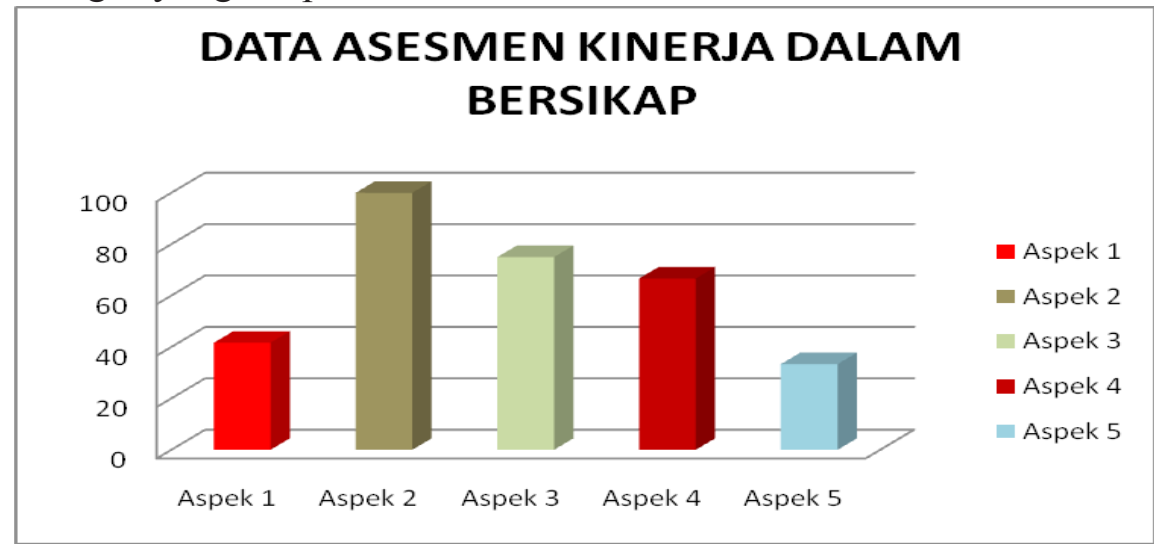

Gambar 3

Data Asesmen Kinerja dalam Bersikap

bersikap paling banyak muncul yaitu aspek 2 yaitu pada sikap tanggung jawab dalam mengerjakan tugas.

Sedangkan untuk penilaian kinerja individu terdapat 3 aspek dan masing-masing aspek memiliki 2 kriteria. Aspek pertama yaitu menjawab pertanyaan, mengajukan pertanyaan, dan mengemukaan pendapat dengan data sebagai berikut. Aspek yang sering muncul adalah aspek 1 yaitu dalam

Tabel 4

Aspek dan Kriteria Kinerja Individu

\begin{tabular}{|c|c|}
\hline Aspek & Kriteria \\
\hline \multirow{2}{*}{$\begin{array}{l}\text { 1. Menjawab pertanyaan yang } \\
\text { diajukan oleh guru }\end{array}$} & a. Bahasa yang digunakan ketika menjawab pertanyaan \\
\hline & b. Keseuaian dengan konsep yang ditanyakan \\
\hline \multirow{2}{*}{ 2. Mengajukan pertanyaan } & a. Bahasa yang digunakan ketika mengajukan pertanyaan \\
\hline & b. Keseuaian dengan konsep yang dipelajari \\
\hline \multirow{2}{*}{$\begin{array}{l}\text { 3. Siswa mengungkapkan } \\
\text { pendapatnya }\end{array}$} & a. Bahasa yang digunakan ketika menjawab pertanyaan \\
\hline & b. Kesesuaian dengan konsep yang dipelajari \\
\hline
\end{tabular}

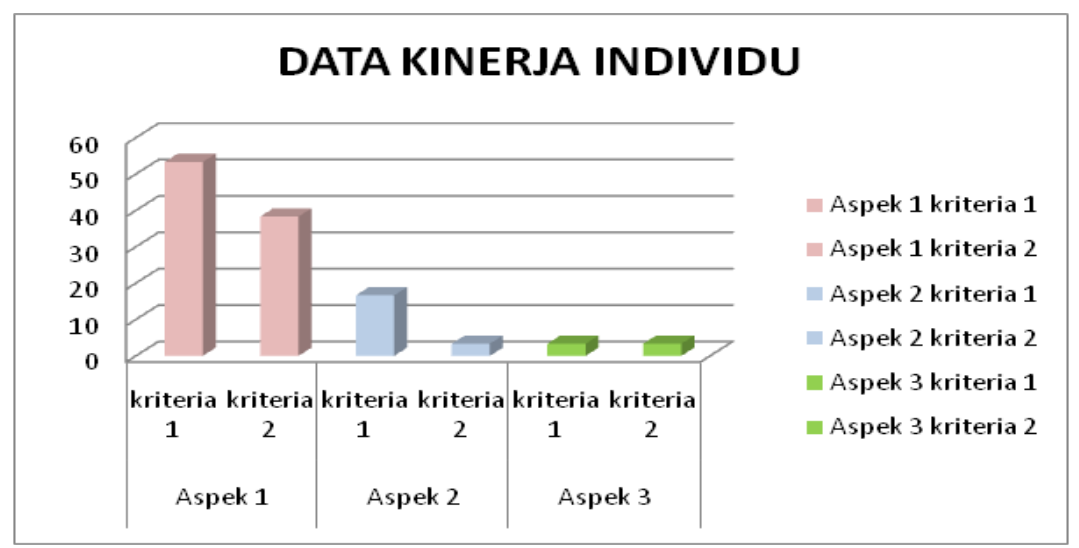

Gambar 4

Data Kinerja Individu

menjawab pertanyaan dari guru.

Dari gambar didapat data tentang bagaimana keterampilan siswa secara kelompok maupun individu selama proses pembelajaran berlangsung. Aspek kinerja produk kelompok paling tinggi yaitu 
kerapihan dalam pembuatan produk dan menggambar kabel pada titik koordinat. Ada bebrapa kelompok yang berhasil membuat produk dengan rapih dan menggambar kabel dengan benar pada titik koordinat.

Pada penggunaan rubrikasesmen kinerja kelompok terdapat 3 aspek. Data paling tinggi saat siswa mengidentifikasi listrik statis, mengidentifikasi sumber arus listrik, dan menampilkan hasil rangkaian listrik. Dimana siswa secara berkelompok bias mengidentuifikasi sumber listrik sampai perwakilan kelompok menampilkan rangkaian listrik yang telah dibuat kelompok. Pada penggunaan rubrik kinerja dalam bersikap paling banyak muncil yaitu aspek 2 yaitu pada sikap tanggung jawab dalam mengerjakan tugas. Dapat dilihat bahwa setiap kelompok mengerjakan tugas masing-masing sangat penuh tanggung jawab. Sedangkan untuk penilaian kinerja individu terdapat 3 aspek dan masing-masing aspek memiliki 2 kriteria. Aspek pertama yaitu menjawab pertanyaan, mengajukan pertanyaan, dan mengemukaan pendapat. Ada beberapasiswa yang selalu mengacungkan tangannya untuk menjawab maupun bertanya.

\section{SIMPULAN}

Berdasarkan hasil penelitian dapat diambil beberapa kesimpulan sebagai berikut:

1. Hasil implementasi pembelajaran berbasis masalah dapat diperoleh data tentang hasil belajar dengan soal HOTSdengan perbandingan antara posttest dan pretest. Dari 20 orang siswa 5 orang belum menunjukan kemajuan dan 15 orang atau sekitar 75\% telah menunjukan kemajuan hasil belajar. Namun perolehan nilai dari soal HOTS ini masih tergolong rendah.

2. Hasil implementasi kinerja dapat dilihat aspek kinerja produk paling tinggi yaitu kerapihan dalam pembuatan produk dan menggambar kabel pada titik koordinat. Pada penggunaan rubrikasesmen kinerja kelompok terdapat 3 aspek. Data paling tinggi saat siswa mengidentifikasi listrik statis, mengidentifikasi sumber arus listrik, dan menampilkan hasil rangkaian listrik.Pada penggunaan rubrik kinerja dalam bersikap paling banyak muncil yaitu aspek 2 yaitu pada sikap tanggung jawab dalam mengerjakan tugas.Sedangkan untuk penilaian kinerja individu terdapat 3 aspek dan masing-masing aspek memiliki 2 kriteria. Aspek pertama yaitu menjawab pertanyaan, mengajukan pertanyaan, dan mengemukakan pendapat.Aspek yang sering muncul adalah aspek 1 yaitu dalam menjawab pertanyaan dari guru.

\section{DAFTAR RUJUKAN}

Duch, Barbara, et, al. (2001). The Power of Problem-Based Learning.Virginia: Stylus Publishing,

Graaff, Erik De \&Kolomos, Annette. 2003. Characteristics of Problem-Based Learning. Delft University of Technology, the Netherlands Aalborg University, Denmark

Hernawan, AsepHerry. Asra. danDewi, L. (2007). BelajardanPembelajaran SD. Bandung: UPI PRESS.

Nasution, S. (2011). Berbagai Pendekatan Dalam Proses BelajarMengajar (Cetakan Kelimabelas). Jakarta: PT BumiAksara

Putra, Juma de. (2013). Inspirasi Mengajarala Harvard University. Yogyakarta: DIVA Press.

Sudjana, Nana. (2006). Penilaian Hasil Proses Belajar Mengajar. Bandung: Remaja Rosdakarya.

Sugiono. (2009). Motode Penelitian Pendidikan. Bandung: Alfabeta 